\title{
A New Approach to Treating Neurodegenerative Otologic Disorders
}

Walter H. Moos, ${ }^{1,2, *}$ Douglas V. Faller, ${ }^{3,4}$ Ioannis P. Glavas, ${ }^{5}$ David N. Harpp, ${ }^{6, *}$ Michael H. Irwin, ${ }^{7}$ Iphigenia Kanara, ${ }^{8}$ Carl A. Pinkert, ${ }^{9}$ Whitney R. Powers, ${ }^{10,11}$ Kosta Steliou, $^{4,12}$ Demetrios G. Vavvas, ${ }^{13,14}$ and Krishna Kodukula ${ }^{2,12,15, *}$

\begin{abstract}
Hearing loss, the most common neurological disorder and the fourth leading cause of years lived with disability, can have profound effects on quality of life. The impact of this "invisible disability," with significant consequences, economic and personal, is most substantial in low- and middle-income countries, where $>80 \%$ of affected people live. Given the importance of hearing for communication, enjoyment, and safety, with up to 500 million affected globally at a cost of nearly $\$ 800$ billion/year, research on new approaches toward prevention and treatment is attracting increased attention. The consequences of noise pollution are largely preventable, but irreversible hearing loss can result from aging, disease, or drug side effects. Once damage occurs, treatment relies on hearing aids and cochlear implants. Preventing, delaying, or reducing some degree of hearing loss may be possible by avoiding excessive noise and addressing major contributory factors such as cardiovascular risk. However, given the magnitude of the problem, these interventions alone are unlikely to be sufficient. Recent advances in understanding principal mechanisms that govern hearing function, together with new drug discovery paradigms designed to identify efficacious therapies, bode well for pharmaceutical intervention. This review surveys various causes of loss of auditory function and discusses potential neurological underpinnings, including mitochondrial dysfunction. Mitochondria mitigate cell protection, survival, and function and may succumb to cumulative degradation of energy production and performance; the end result is cell death. Energy-demanding neurons and vestibulocochlear hair cells are vulnerable to mitochondrial dysfunction, and hearing impairment and deafness are characteristic of neurodegenerative mitochondrial disease phenotypes. Beyond acting as cellular powerhouses, mitochondria regulate immune responses to infections, and studies of this phenomenon have aided in identifying nuclear factor kappa B and nuclear factor erythroid 2-related factor 2/antioxidant response element signaling as targets for discovery of otologic drugs, respectively, suppressing or upregulating these pathways. Treatment with free radical scavenging antioxidants is one therapeutic approach, with lipoic
\end{abstract}

Dedicated to the late Richard H. Tomlinson, Canadian philanthropist and champion of functional hearing aids for the public.

${ }^{1}$ Department of Pharmaceutical Chemistry, School of Pharmacy, University of California San Francisco, San Francisco, California.

${ }^{2}$ Shang Pharma Innovation, Inc., South San Francisco, California.

${ }^{3}$ Department of Medicine, Boston University School of Medicine, Boston, Massachusetts.

${ }^{4}$ Cancer Research Center, Boston University School of Medicine, Boston, Massachusetts.

${ }^{5}$ Department of Ophthalmology, New York University School of Medicine, New York, New York.

${ }^{6}$ Department of Chemistry, Office for Science \& Society, McGill University, Montreal, Canada.

${ }^{7}$ Department of Pathobiology, College of Veterinary Medicine, Auburn University, Auburn, Alabama.

${ }^{8}$ Embassy of Greece in Moscow, Moscow, Russia.

${ }^{9}$ Department of Biological Sciences, College of Arts and Sciences, The University of Alabama, Tuscaloosa, Alabama.

${ }^{10}$ Department of Health Sciences, Boston University, Boston, Massachusetts.

${ }^{11}$ Department of Anatomy, Boston University School of Medicine, Boston, Massachusetts.

${ }^{12}$ PhenoMatriX, Inc., Natick, Massachusetts.

${ }^{13}$ Retina Service, Angiogenesis Laboratory, Massachusetts Eye and Ear Infirmary, Boston, Massachusetts.

${ }^{14}$ Department of Ophthalmology, Harvard Medical School, Boston, Massachusetts.

${ }^{15}$ Bridgewater College, Bridgewater, Virginia.

*Address correspondence to: Walter H. Moos, PhD, Department of Pharmaceutical Chemistry, School of Pharmacy, University of California San Francisco, UCSF Box 2280, 600 16th Street, Genentech Hall S512D, San Francisco, CA 94143, E-mail: walter.moos@ucsf.edu or David N. Harpp, PhD, Department of Chemistry, Office for Science \& Society, McGill University, 801 Sherbrooke Street West, Montreal H3A 0B8, QC, Canada, E-mail: david.n.harpp@mcgill.ca or Krishna Kodukula, PhD, ShangPharma Innovation, Inc., 280 Utah Avenue, South San Francisco, CA 94080, E-mail: kkodukula@gmail.com

(C) Walter H. Moos et al. 2018; Published by Mary Ann Liebert, Inc. This Open Access article is distributed under the terms of the Creative Commons License (http://creativecommons.org/licenses/by/4.0), which permits unrestricted use, distribution, and reproduction in any medium, provided the original work is properly cited. 
acid and corresponding carnitine esters exhibiting improved biodistribution and other features showing promise. These compounds are also histone deacetylase (HDAC) inhibitors, adding epigenetic modulation to the mechanistic milieu through which they act. These data suggest that new drugs targeting mitochondrial dysfunction and modulating epigenetic pathways via HDAC inhibition or other mechanisms hold great promise.

Keywords: carnitine esters; epigenetics; hearing loss; lipoic acid; mitochondrial dysfunction; pharmaceutical

\section{Background}

Vision is the pre-eminent sensory means by which we navigate the world around us, ${ }^{1}$ while the ability to hear endows us with the power of voice communication. It enriches our lives with the sound of music and alerts us to imminent danger that can be heard although perhaps not seen. The Greek physician-philosopher Alcmaeon of Croton $^{2-5}$ and his two protagonist followers, Praxagoras of $\mathrm{Kos}^{3,6}$ and the great Alexandrian physician of Chalcedon, ${ }^{7}$ Herophilus, ${ }^{2,3}$ propounded that hearing is a construct of the brain, where external sound channeled to it through the ears (transduced into sensorineural signals) is interpreted. ${ }^{6}$

Hearing loss is the most common neurological disorder affecting people worldwide. ${ }^{8}$ The World Health Organization (WHO) estimates that the annual cost of unaddressed hearing loss is in the range of $\$ 750$ 790 billion globally. ${ }^{9}$ In the "Global Burden of Disease," impaired hearing represents the fourth leading cause of disability worldwide. ${ }^{10-12}$ About $5-7 \%$ of the world's population ( $\sim 360-500$ million people) has a hearing disability $^{12,13}$ that is severe enough in more than $80 \%$ of people older than 85 years to interfere with their ability to communicate effectively. ${ }^{10}$ In children, impaired hearing can impinge on their academic potential and social development ${ }^{13}$ with lifelong adverse consequences. ${ }^{14}$ Hearing loss due to mechanical (conductive) and/or anatomical issues in the outer and/or middle ear (Fig. 1) is less prevalent than that resulting from dysfunction in the cochlea and/or the auditory nerves (sensorineural) in the inner ear or a mixture of conductive and sensorineural components. ${ }^{10,15}$

Although the array of techniques used in the diagnosis of sensorineural hearing loss (SNHL, the predominant form of hearing loss worldwide) is progressively being expanded and refined, ${ }^{14}$ developing therapeutics to treat the onset of SNHL is proving to be considerably more difficult to realize ${ }^{13,14}$-thus placing a premium emphasis on prevention. ${ }^{12,16}$ A compelling case for prevention is noise-induced hearing loss (NIHL), one of the most common types of SNHL. ${ }^{17,18}$ Noise pollution is a growing health problem around the world. ${ }^{19-22}$
For example, in the United States alone, it is estimated that more than $25 \%$ of the adult population has measurable hearing loss caused by exposure to harmful noise. ${ }^{10}$ Irreversible hearing loss can also be the product of disease $^{12,16,23,24}$ and is often an unfortunate side effect of the aminoglycoside antibiotics ${ }^{25-30}$ and platin-based anticancer drugs. ${ }^{10,27,28,30-36}$ Regrettably, once damage has occurred, hearing aids and cochlear implantation are the only compensatory options presently available for affected individuals. ${ }^{37}$

There is a substantial and growing worldwide unmet medical need for a pharmaceutical approach to treating hearing impairment. ${ }^{38,39}$ SNHL results from damage to the organ of Corti (Fig. 1), causing the degeneration of spiral ganglion neurons due to excessive injury and/ or untoward death of cochlear hair cells in the inner ear, ${ }^{10,40,41}$ in most cases caused by internal or external pathologic factors, including infectious or inflammatory processes, ototoxic drugs, noise overstimulation, as well as the normal aging process. ${ }^{13,16,25,40,42}$ Unexpectedly, a recent meta-analysis of numerous epidemiological studies exposed a possible link between presbycusis (also known as age-related hearing loss, ARHL) and cognitive decline, cognitive impairment, and dementia-suggesting that ARHL may be a relevant biomarker and a targetable modifiable risk factor for dementia. ${ }^{43-46}$ However, given that advanced age itself is a leading risk factor for dementia, ${ }^{1,47-49}$ the meta-analysis correlation is not surprising.

\section{Mitochondrial Dysfunction in Hearing Loss}

Mitochondria mitigate cell protection, survival, and function $^{1,50-52}$ (Hoffman ME, Augsburger BN, Foradori CD, et al. Neuroprotective effects of carnitinoid compounds in rodent cellular and in vivo models of mitochondrial complex I dysfunction. 2018; submitted) and, over time, they succumb to an increasing cumulative degradation of their cellular energy production and performance-driving the cell toward death (apoptosis) and/or premature senescence (Hoffman et al., submitted). ${ }^{40,47,48,53-59}$ Energy-demanding cells such as neurons and the vestibulocochlear hair cells (Fig. 1) are especially vulnerable to mitochondrial dysfunction ${ }^{60,61}$ 


\section{b}
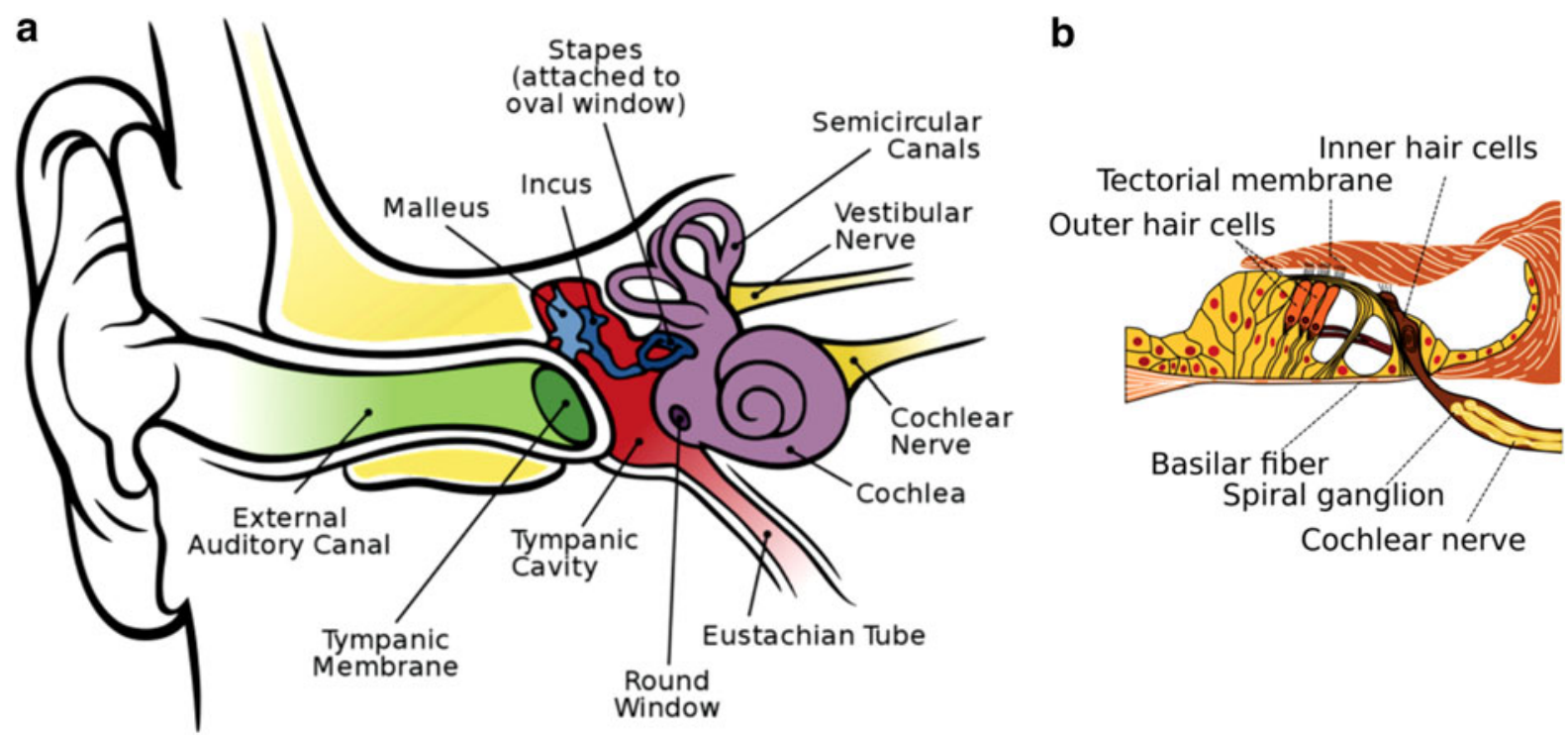

FIG. 1. Anatomy of the human ear. (a) The outer ear includes the ear lobe and auditory canal; middle ear, the tympanic membrane and cavity; the inner ear, the hearing (cochlea) and balance (vestibular system) organs and the attached associated nerves connecting to the brain. (Figure reproduced from Chittka $\mathrm{L}$, Brockmann A. Perception space-the final frontier. PLoS Biol. 2005;3(4):e137. CC BY 2.5 (https://creative commons.org/licenses/by/2.5/deed.en), via Wikimedia Commons. Original File URL: https://commons .wikimedia.org/wiki/File:Anatomy_of_the_Human_Ear_en.svg) (b) Expanded cross section of the cochlea (organ of Corti) showing the outer and inner hair cells, and the spiral ganglion of the cochlear nerve. (Cochlea-crosssection.png. CC BY-SA 3.0 US (https://creativecommons.org/licenses/by-sa/3.0/us/), via Wikimedia Commons. Original File URL: https://commons.wikimedia.org/wiki/File:Organ_of_corti.svg)

and, consequently, hearing impairment/deafness is a characteristic clinical symptom of several neurodegenerative mitochondrial disease phenotypes. ${ }^{24,25,44,62-66}$

Focusing on the genetic basis of hearing loss, it is worth noting that many mutations in the mitochondrial genome (mitochondrial DNA, mtDNA), as well as in the nuclear genome (nuclear DNA, nDNA), are known to cause hearing deficits (Table 1). ${ }^{24,62,63,65-67}$ Alterations in certain regions of mtDNA associated with deafness are also associated with a host of other disorders, such as myopathy including cardiomyopathy, diabetes, and parkinsonism. ${ }^{68-72}$

In addition, mitochondria are key regulators of our innate and adaptive immune responses to viral

Table 1. Representative Mitochondrial Disorders Associated with Hearing Impairment/Deafness

\begin{tabular}{|c|c|c|c|}
\hline Disease & Abbreviation & mtDNA/RNA ${ }^{a}$ & $\begin{array}{l}\text { Defect, presence of symptom, } \\
\text { sign or finding, and other notes }\end{array}$ \\
\hline Aminoglycoside-induced deafness & AID & Mutation in rRNA & Also associated with Parkinson's disease \\
\hline Kearns-Sayre syndrome & KSS & Large-scale deletions & Possible presence of sensorineural hearing loss \\
\hline $\begin{array}{l}\text { Mitochondrial encephalomyopathy, } \\
\text { lactic acidosis, and stroke-like episodes }\end{array}$ & MELAS & Mutation in tRNA & \\
\hline Maternally inherited deafness and diabetes & MIDD & Mutation in RNA & Phenotypically and genotypically heterogeneous \\
\hline Mohr-Tranebjaerg syndrome & MTS & Mutations in nDNA & $\begin{array}{l}\text { Causes defects in mitochondrial protein } \\
\text { import machinery }\end{array}$ \\
\hline Myoclonic epilepsy with ragged red fibers & MERFF & Mutation in tRNA & \\
\hline Neuropathy, ataxia, and retinitis pigmentosa & NARP & Mutation in mRNA & Possible presence of sensorineural hearing loss \\
\hline Progressive external ophthalmoplegia & PEO & Multiple deletions & $\begin{array}{l}\text { Ophthalmoplegia is a clinical hallmark of } \\
\text { multiple deletions in mtDNA }\end{array}$ \\
\hline
\end{tabular}

aunless otherwise noted. 
infections. ${ }^{50,73-76}$ Often overlooked among the many causes of impaired hearing, including deafness, is virus-induced hearing loss. ${ }^{7-79}$ Although the mechanisms of hearing loss/deafness associated with viral infections remain largely undefined, ${ }^{78,80}$ viral infections activate a cascade of mitochondrial antiviral innate immune responses that include nuclear factor kappa $B$ $(\mathrm{NF}-\kappa \mathrm{B})^{50,75,76,80,81}$ and nuclear factor erythroid 2related factor 2 (Nrf2)/antioxidant response element (ARE) signaling pathways. ${ }^{1,50,76}$

Unmitigated oxidative stress (which is primarily caused by mitochondrial dysfunction) and epigenetically altered expression of genes sensing oxidative stress are significant contributors to the pathogenicity of neurodegenerative disorders (Hoffman et al., submitted). ${ }^{47,52,54,76,82,83}$ While a full understanding of these pathways awaits further study, it seems clear that epigenetics plays a significant role. Mammalian vestibulocochlear hair cells are a stress-sensitive, nonregenerative cell type and, like the retinal cells of the eye, ${ }^{1}$ are not replaced when they are injured or die. ${ }^{10,13,14,29,57,60,82,84-86}$ Interestingly, emerging research indicates we selectively amplify directional sound in a noisy environment by unconsciously utilizing eye-ear coordination to integrate visual cues with the auditory information. ${ }^{87,88}$ Assessing vision and oculomotor function is essential in the diagnostic evaluation of vestibulocochlear auditory impairments, ${ }^{89}$ particularly in patients with idiopathic etiology. ${ }^{90,91}$

\section{$\alpha$-Lipoic Acid, L-Carnitine, and Butyrate}

Impressive advances in gene therapy ${ }^{8,14,92-94}$ and regenerative medicine are making inroads toward regenerating hair cells with the aim of reversing hearing loss. ${ }^{41,95}$ Some of the achievements demonstrate therapeutic potential, ${ }^{8,86}$ but a clinical application is still a long way off. ${ }^{24,39}$ In the more immediate future, shielding hair cells from oxidative damage and/or rescuing injured hair cells from falling into apoptosis by pharmacological treatment with free radical scavenging antioxidant compounds portend a promising therapeutic approach. $^{13,14,29,30,57,96-99}$

Upregulating $N r f 2 / A R E$ gene expression pathways and/or suppressing NF- $\kappa$ B signaling are cogent targets for pharmaceutical intervention strategies. ${ }^{34}$ Many natural and synthetic compounds are known inhibitors of NF- $\kappa \mathrm{B}$ signaling ${ }^{100}$-butyric acid (butyrate) ${ }^{50,101-105}$ and $\alpha$-lipoic acid (5-[(3R)-1,2-dithiolan-3-yl]pentanoic acid) ${ }^{50,106-110}$ (Fig. 2) are among them. Importantly, butyric acid and $\alpha$-lipoic acid (ALA), as well as their respective corresponding L-carnitine esters PMX550DBr and PMX500FI (Fig. 2), also act as antioxidant histone deacetylase (HDAC) inhibitors (HDACi) (Hoffman et al., submitted). ${ }^{47,50,54}$ noted for effecting favorable epigenetic modulation of the cell survival protein, B cell lymphoma $2(\mathrm{Bcl}-2)$ with respect to the proapoptotic protein, $\mathrm{Bcl}-2$-associated $\mathrm{X}$ protein $(\mathrm{BAX})$ in a BAX/Bcl-2 ratio of 1:2..$^{54,110-113}$ Again, note the implied potential of drugs that modulate epigenetic pathways.

ALA has been extensively researched as a neuroprotectant, ${ }^{114-119}$ acting on signaling mechanisms through both receptor-mediated pathways and nonreceptormediated antioxidant processes in a variety of cell types ${ }^{110,115,116,119,120}$-including cochlear hair cells. ${ }^{31,121,122}$ In humans, ALA is a functionally versatile endogenous molecule enzymatically synthesized in mitochondria from octanoic acid. ${ }^{123}$ It is a key cofactor in the

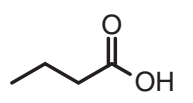

Butyric acid



$\alpha$-Lipoic acid (ALA) 5-[(3R)-1,2-dithiolan-3-yl]pentanoic acid

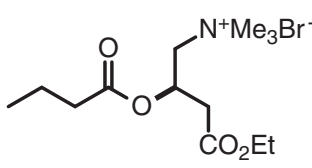

$\mathrm{PMX550 \textrm {DBr }}$

Butyryl-L-carnitine ethyl ester bromide

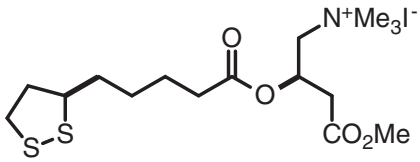

PMX500FI

Lipoyl-L-carnitine methyl ester iodide

FIG. 2. Chemical structures of butyric acid, ALA, and their corresponding carnitine esters. ALA, $\alpha$-lipoic acid. 
construction of vital metabolic multienzyme complexes, including pyruvate dehydrogenase and the glycine cleavage system. ${ }^{123}$ It is also a strong antioxidant ${ }^{1,119,124,125}$ and anti-inflammatory ${ }^{109,119,125}$ agent capable of activating and modulating signal transduction pathways, ${ }^{109,119,126}$ upregulating the expression of nerve growth factor, and augmenting the conduction velocity of motor nerves. ${ }^{127}$

The expression of $\sim 1 \%(\sim 200-250$ genes $)$ of the protein-coding human genome is modulated in concert with the Nrf2/ARE signaling pathway. ${ }^{117,128}$ ALA is a potent activator of $\mathrm{Nrf} 2$, a transcription factor encoded by NFE2L2 that helps regulate cellular redox balance and protective antioxidant and phase II detoxification responses in mammals. ${ }^{50}$ Dietary antioxidant supplements are commonly sought by patients and caregivers for treating primary mitochondrial disorders. ${ }^{23,65}$ The role of antioxidants in prevention of age-related hearing loss has been reviewed by Tavanai and Mohammadkhani. ${ }^{129}$ In one of the reviewed studies, C57BL/6 mice fed with control diet or diet containing 1 of 17 antioxidant compounds (acetyl-L-carnitine, $\mathrm{N}$-acetyl-Lcysteine (NAC), ALA, carotene, carnosine, coenzyme $\mathrm{Q}_{10}$, curcumin, tocopherol, epigallocatechin-3-gallate, gallic acid, lutein, lycopene, melatonin, proanthocyanidin, quercetin, resveratrol, or tannic acid), ARHL was nearly completely prevented by ALA and coenzyme $\mathrm{Q}_{10}$ and partially by NAC, but not by the other compounds. ${ }^{130}$ Unfortunately, this strategy showed no significant benefit in an interventional human study. ${ }^{131}$

However, the results from the Polanski and $\mathrm{Cruz}^{131}$ study may not truly address the ability of antioxidants to prevent ARHL because the design of the study was not directed toward prevention, and damaged cochlear hair cells are not restored by antioxidants. ${ }^{129}$ In studies aimed at preventing hearing loss in aged animals, ALA was shown to confer significant hearing preservation. ${ }^{34,108} \mathrm{Sim}$ ilar results between human and animal studies ${ }^{99}$ were also observed with the use of L-carnitine-an endogenously synthesized molecule mostly obtained from the diet. ${ }^{65}$

$\mathrm{NF}-\kappa \mathrm{B}$ is a transcription factor that regulates the expression of a variety of genes involved in inflammation and immunity. ${ }^{81,104,105}$ Sodium butyrate is a welldocumented HDAC inhibitor ${ }^{18,27,54,101,105}$ that has demonstrated anti-inflammatory NF- $\kappa \mathrm{B}$ inhibition properties. ${ }^{50,101-105}$ Butyrate mediates NF- $\kappa \mathrm{B}$ activation by rescuing the redox machinery and controlling reactive oxygen species ${ }^{105}$ that are highly injurious to hair cells ${ }^{18,132}$ by suppressing the NF- $\kappa \mathrm{B}$ signaling pathways. ${ }^{105}$

Although ALA and butyrate are common food and diet supplements that can be safely taken in high<smiles>CC(=O)Nc1ccc(O)cc1</smiles><smiles>CC(C)Cc1ccc(C(C)C(=O)O)cc1</smiles>

ibuprofen<smiles>[M]C(CCCN(CC)CC)Nc1ccnc2cc(Cl)ccc12</smiles>

chloroquine valproic acid<smiles>CCCC(CCC)C(=O)O</smiles>

capreomycin<smiles>NS(=O)(=O)c1cc(Cl)c(NCc2ccco2)cc1C(=O)O</smiles>

furosemide

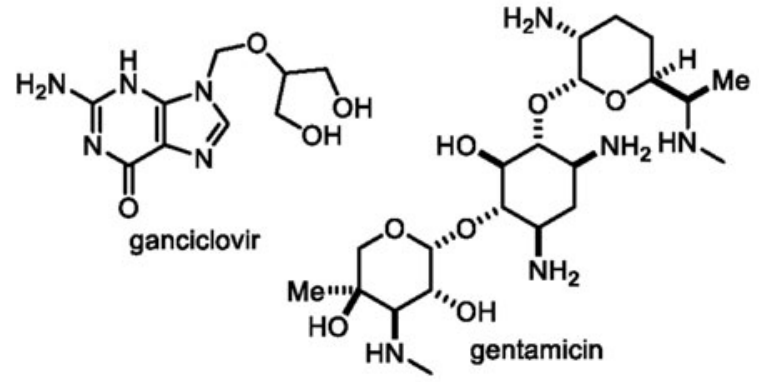



FIG. 3. Wide ranging chemical structures of potentially ototoxic drugs. 
Table 2. Selected Key Points

- Roughly 1 in 15 people worldwide-about 500 million-suffer from disabling hearing loss; two to three times that number have mild-tocomplete hearing loss. ${ }^{12,13}$

- Recent studies proclaim hearing problems as the fourth leading cause of YLDs; clearly a major global health concern. ${ }^{10-12}$

- Hearing impairment has been called an "invisible disability" despite its significant consequences, economic and personal; the impact is most substantial in LMICs, where $>80 \%$ of people with hearing loss reside. ${ }^{44}$

- Noise exposure is a major cause of deafness and hearing impairment (i.e., noise-induced hearing loss); cardiovascular risk caused by diabetes and smoking is also associated with hearing loss. ${ }^{22}$

- Hearing impairment in children and adults may also present as sequelae of cytomegalovirus, Ebola virus, and other serious infections. ${ }^{14,75,77,121}$

- Advanced age is a major risk factor for hearing loss (i.e., presbycusis, age-related hearing loss), with U.S. prevalence nearly $70 \%$ over age 70; indeed, age-related hearing loss may prove to be a useful biomarker and treatable risk factor for cognitive decline or impairment, including Alzheimer's disease. ${ }^{43-46}$

- Hearing loss has been observed following TBI, and while it is significant clinically it is yet to be well characterized. ${ }^{92,136}$

- Genetics, both mitochondrial and nuclear, and demographics (educational level, race/ethnicity, sex) have an influence on, or are associated with, hearing disorders. ${ }^{24,62,63,65,66,72,82}$

- The most common congenital sensory impairment is hearing loss, affecting between 1 in 300 to 500 newborns and children to the age of 4; one example results from disruption of a gene that encodes a major component of cochlear gap junctions. ${ }^{137}$

- It is not uncommon to see links between sensorineural deficits in both the ear and the eye; RP, an inherited eye disease, is in some cases associated with reduced hearing ability. ${ }^{65,66,75,89}$

- Sensorineural hearing loss is found in mitochondrial respiratory chain disorders, and mtDNA mutations represent one of the most important causes of hearing loss (Table 1$)^{24,62,63,65,66}$; given the high energy demands of hearing, mitochondrial involvement should not be a surprise. . $^{6,61}$

- Certain drugs (Fig. 3), notably aminoglycoside antibiotics (gentamicin), antivirals (ganciclovir), antifungals (amphotericin B), antimalarials (chloroquine), antituberculosis agents (capreomycin), cardiovascular drugs (furosemide), anticonvulsants (valproic acid), cisplatin (platinol), and immunosuppressants (tacrolimus), can result in significant hearing loss. ${ }^{16,28}$ Ototoxicity is a potential side effect of some commonly used NSAID and related medications, including acetaminophen (paracetamol) and ibuprofen when taken in very high doses or used chronically ( $\geq 2$ days/week). ${ }^{42}$ In lieu of a recent study suggesting that, if started early enough, a daily regimen of ibuprofen can prevent the onset of Alzheimer's disease, ${ }^{138}$ ototoxicity in this protocol is an important consideration to take into account.

- From a pharmaceutical perspective, the chemical structural diversity (Fig. 3) of potentially ototoxic drugs is noteworthy.

- Drug discovery to identify novel therapeutics that protect hair cells from toxic insults is experimentally challenging owing to the inaccessibility of the inner ear, but zebrafish and other animal models have been explored; screens have identified multiple potential drug classes of interest, for example, antioxidants, ${ }^{122}$ and other compounds acting on classical GPCR neurotransmitter systems (i.e., adrenergic, dopaminergic, serotoninergic) and estrogen receptor modulators. $28,29,32,37,57,65,99$

- Biotechnology and pharmaceutical companies have recognized the unmet medical need and therapeutic potential of new drugs for hearing impairment, as exemplified by ventures such as Aurin, Auris, Autifony, Decibel, Frequency, Novus, Otonomy, Sensorion, and Sound, among others ${ }^{10,13,31,97}$; still relatively untapped in this respect are epigenetic and mitochondrial targets. $8,14,18,26,27,30,34,57,82,98,99,132,139-141$

GPCR, G-protein-coupled receptor; LMICs, low- and middle-income countries; NSAID, nonsteroidal anti-inflammatory drug; RP, retinitis pigmentosa; TBI, traumatic brain injury; YLDs, years lived with disability. doses, their bioavailability is not prolonged or sustained at an effective therapeutic level. ${ }^{50}$ Furthermore, a recent Phase I clinical trial in age-related macular degeneration evaluating the safety and tolerability of ALA in 15 subjects, 65 years of age or older, showed that high doses (800-1200 mg) of racemic ALA cannot be tolerated very well by patients. ${ }^{133}$ Thus, in the treatment of hearing loss, a need for ALA and butyrate derivatives having more clinically suitable pharmacokinetics is a challenging pharmaceutical objective.

\section{Concluding Remarks}

Hearing impairment is a major global health concern; its massive impact seemingly unrecognized until recently, and the affected population largely untreated. Preventing, or at least delaying or reducing, some hearing loss may be possible by avoiding excessive noise exposure and addressing contributory factors such as cardiovascular risk, infectious diseases, neurological disorders, and drug toxicity. However, these interventions will not be sufficient given the sheer magnitude of the problem. Thus, in view of recent advances in our understanding of the underlying mechanistic pathways-both mitochondrial and epigenetic-that govern hearing function, coupled with new drug discovery paradigms that can today be exploited to identify new and effective therapies, the time is ripe to tackle hearing loss with novel medicines. Alcmaeon of Croton remarked that vision and hearing are constructs of the brain. We see and hear in our dreams and in some aspects of disease conditions, such as high fever, schizophrenia, psychosis, or the later stages of dementia, and our dreams may blend into our conscious state immersed in auditory and/or visual hallucinations and delusions. The most common hallucination in schizophrenia is hearing voices. ${ }^{134,135}$ Finally, readers are directed to Table 2 for a summary of key points related to otologic disorders.

\section{Acknowledgments}

We gratefully acknowledge the generous financial support from the MitoCure Foundation and thank Dr. Robert J. Zamboni (Zamboni Chem Solutions, McGill University) for his invaluable advice and helpful discussions in the preparation of this article.

\section{Authors' Contributions}

All authors contributed to the writing of this article and agreed to its final content. 


\section{Author Disclosure Statement}

K.S. owns shares in PhenoMatriX, Inc. K.K. and W.H.M. consult with and/or serve on the boards of various biotechnology and pharmaceutical companies from time to time, where they may receive compensation including stock options, and they receive compensation from ShangPharma Innovation, Inc., a healthcare venture capital firm. For all other authors, no competing financial interests exist.

\section{References}

1. Moos WH, Faller DV, Glavas IP, et al. Epigenetic treatment of neurodegenerative ophthalmic disorders: an eye toward the future. BioRes Open Access. 2017;6:169-181.

2. Bowder D. (ed.) Who was who in the Greek world: 776 BC-30 BC. Cornell University Press: Ithaca, NY, 1982.

3. Sebastian A. A Dictionary of the History of Medicine. Routledge: London, p. 788; 1999. eBook Available at: www.taylorfrancis.com/books/ 9781351470001 Accessed February 6, 2018.

4. Debernardi A, Sala E, D'Aliberti G, et al. Alcmaeon of Croton. Neurosurgery. 2010;66:247-252.

5. Zemelka AM. Alcmaeon of Croton-father of neuroscience? Brain, mind and senses in the Alcmaeon's study. J Neurol Neurosci. 2017;8:3.

6. Panegyres KP, Panegyres PK. The ancient Greek discovery of the nervous system: Alcmaeon, Praxagoras and Herophilus. J Clin Neurosci. 2016; 29:21-24.

7. Standring S. A brief history of topographical anatomy. J Anat. 2016;229: 32-62.

8. Ahmed $\mathrm{H}$, Shubina-Oleinik $\mathrm{O}$, Holt JR. Emerging gene therapies for genetic hearing loss. JARO. 2017;18:649-670.

9. WHO Report. Global costs of unaddressed hearing loss and costeffectiveness of interventions. 2017. Available at: http://apps.who.int/ iris/bitstream/10665/254659/1/9789241512046-eng.pdf Accessed July 18, 2018.

10. Cunningham LL, Tucci DL. Hearing loss in adults. N Engl J Med. 2017;377: 2465-2473.

11. Tucci DL, Wilson BS, O'Donoghue GM. The growing-and now alarmingburden of hearing loss worldwide. Otol Neurotol. 2017;38:1387-1388.

12. Wilson BS, Tucci DL, Merson MH, et al. Global hearing health care: new findings and perspectives. Lancet. 2017;390:2503-2515.

13. Crowson MG, Hertzano R, Tucci DL. Emerging therapies for sensorineural hearing loss. Otol Neurotol. 2017;38:792-803.

14. Ralli $M$, Rolesi $R$, Anzivino $R$, et al. Acquired sensorineural hearing loss in children: current research and therapeutic perspectives. Acta Otorhinolaryngol Ital. 2017;37:500-508.

15. Bauer CA. Tinnitus. N Engl J Med. 2018;378:1224-1231.

16. Brown CS, Emmett SD, Robler SK, et al. Global hearing loss prevention. Otolaryngol Clin N Am. 2018;51:575-592.

17. Sha SH, Schacht J. Emerging therapeutic interventions against noiseinduced hearing loss. Expert Opin Invest Drugs. 2017;26:85-96.

18. Yang D-H, Jing Xie J, Liu K, et al. The histone deacetylase inhibitor sodium butyrate protects against noise-induced hearing loss in Guinea pigs. Neurosci Lett. 2017;660:140-146.

19. Frenzilli G, Ryskalin L, Ferrucci M, et al. Loud noise exposure produces DNA, neurotransmitter and morphological damage within specific brain areas. Front Neuroanat. 2017;11:49.

20. Rimantho D, Hanantya MW. Enhancing the management of the noise level using six sigma method: a case study on the machining industry. IOP Conf Ser Mater Sci Eng. 2017;277:012055.

21. Yao CMKL, Ma AK, Cushing SL, et al. Noise exposure while commuting in Toronto-a study of personal and public transportation in Toronto. J Otolaryngol Head Neck Surg. 2017;46:62.

22. Münzel T, Sørensen M, Schmidt F, et al. The adverse effects of environmental noise exposure on oxidative stress and cardiovascular risk. Antioxid Redox Signal. 2018;28:873-908.

23. El-Hattab AW, Zarante AM, Almannai M, et al. Therapies for mitochondrial diseases and current clinical trials. Mol Genet Metab. 2017;122:1-9.
24. Teplova VV, Deryabina YI, Isakova EP. Mitochondrial cytopathies: their causes and correction pathways. Biochem Mosc Suppl Ser A Membr Cell Biol. 2017;11:87-102.

25. Kamogashira T, Fujimoto C, Yamasoba T. Reactive oxygen species, apoptosis, and mitochondrial dysfunction in hearing loss. BioMed Res Int. 2015;2015:617207.

26. Wang J, Wang Y, Chen X, et al. Histone deacetylase inhibitor sodium butyrate attenuates gentamicin-induced hearing loss in vivo. Am J Otolaryngol. 2015;36:242-248.

27. Chen $D, X u M, W u B$, et al. Histone deacetylases in hearing loss: current perspectives for therapy. J Otol. 2017;12:47.e54.

28. Jiang M, Karasawa T, Steyger PS. Aminoglycoside-induced cochleotoxicity: a review. Front Cell Neurosci. 2017;11:308.

29. Chowdhury S, Owens KN, Herr J, et al. Phenotypic optimization of urea-thiophene carboxamides to yield potent, well tolerated, and orally active protective agents against aminoglycoside-induced hearing loss. $J$ Med Chem. 2018;61:84-97.

30. Kuang X, Sun Y, Wang Z, et al. A mitochondrial targeting tetrapeptide Bendavia protects lateral line hair cells from gentamicin exposure. J Appl Toxicol. 2018;38:376-384.

31. Noack V, Pak K, Jalota $R$, et al. An antioxidant screen identifies candidates for protection of cochlear hair cells from gentamicin toxicity. Front Cell Neurosci. 2017;11:242.

32. Sheth S, Mukherjea D, Rybak LP, et al. Mechanisms of cisplatin-induced ototoxicity and otoprotection. Front Cell Neurosci. 2017;11:338.

33. Young MJ. Off-target effects of drugs that disrupt human mitochondrial DNA maintenance. Front Mol Biosci. 2017;4:74.

34. Hazlitt RA, Min J, Zuo J. Progress in the development of preventative drugs for cisplatin-induced hearing loss. J Med Chem 2018 [Epub ahead of print]. DOI:10.1021/acs.jmedchem.7b01653.

35. Tang L-Q, Chen D-P, Guo L, et al. Concurrent chemoradiotherapy with nedaplatin versus cisplatin in stage II-IVB nasopharyngeal carcinoma: an open-label, non-inferiority, randomised phase 3 trial. Lancet Oncol. 2018;19:461-473.

36. Teitz T, Fang J, Goktug AN, et al. CDK2 inhibitors as candidate therapeutics for cisplatin- and noise-induced hearing loss. J Exp Med. 2018; 215:1187-1203.

37. O'Sullivan ME, Cheng AG. Mind your ears: a new antidote to aminoglycoside toxicity? J Med Chem. 2018;61:81-83.

38. Davis R. Long-term noise exposures: a brief review. Hear Res. 2017;349: 31-33.

39. Schilder AGM, Blackshaw $H$, Lenarz $T$, et al. Biological therapies of the inner ear: what otologists need to consider. Otol Neurotol. 2018;39: 135-137.

40. Dinh $\mathrm{CT}$, Goncalves $\mathrm{S}$, Bas $\mathrm{E}$, et al. Molecular regulation of auditory hair cell death and approaches to protect sensory receptor cells and/or stimulate repair following acoustic trauma. Front Cell Neurosci. 2015; 9:96.

41. McLean WJ, Yin X, Lu L, et al. Clonal expansion of Lgr5-positive cells from mammalian cochlea and high-purity generation of sensory hair cells. Cell Rep. 2017;18:1917-1929.

42. Lin BM, Curhan SG, Wang M, et al. Duration of analgesic use and risk of hearing loss in women. Am J Epidemiol. 2017;185:40-47.

43. Lin VYW, Black SE. Linking deafness and dementia: challenges and opportunities. Otol Neurotol. 2017;38:e237-e239.

44. Livingston G, Sommerlad A, Orgeta V, et al. Dementia prevention, intervention, and care. Lancet. 2017;390:2673-2734.

45. Larson EB. Prevention of late-life dementia: no magic bullet. Ann Intern Med. 2018;168:77-79.

46. Loughrey DG, Kelly ME, Kelley GA, et al. Association of age-related hearing loss with cognitive function, cognitive impairment, and dementia. A systematic review and meta-analysis. JAMA Otolaryngol Head Neck Surg. 2018;144:115-126.

47. Irwin $\mathrm{MH}$, Moos WH, Faller DV, et al. Epigenetic treatment of neurodegenerative disorders: Alzheimer and Parkinson diseases. Drug Dev Res. 2016;77:109-123.

48. Moos WH, Faller DV, Harpp DN, et al. Microbiota and neurological disorders: a gut feeling. BioRes Open Access. 2016;5:137-145.

49. Declerck K, Vanden Berghe W. Back to the future: epigenetic clock plasticity towards healthy aging. Mech Ageing Dev. 2018. [Epub ahead of print]; DOI: 10.1016/j.mad.2018.01.002. 
50. Moos WH, Pinkert $\mathrm{CA}$, Irwin $\mathrm{MH}$, et al. Epigenetic treatment of persistent viral infections. Drug Dev Res. 2017;78:24-36.

51. Rambold AS, Pearce EL. Mitochondrial dynamics at the interface of immune cell metabolism and function. Trends Immunol. 2018;39:6-18.

52. Sorrentino V, Menzies KJ, Auwerx J. Repairing mitochondrial dysfunction in disease. Annu Rev Pharmacol Toxicol. 2018:58:353-389.

53. Garatachea N, Pareja-Galeano H, Sanchis-Gomar F, et al. Exercise attenuates the major hallmarks of aging. Rejuvenation Res. 2015;18:57-89.

54. Moos WH, Maneta E, Pinkert CA, et al. Epigenetic treatment of neuropsychiatric disorders: autism and schizophrenia. Drug Dev Res. 2016; 77:53-72.

55. Grimm A, Eckert A. Brain aging and neurodegeneration: from a mitochondrial point of view. J Neurochem. 2017;143:418-431.

56. de Magalhães JP, Passos JF. Stress, cell senescence and organismal ageing. Mech Ageing Dev. 2018;170:2-9.

57. Hu W, Wu J, Jiang W, et al. MicroRNAs and presbycusis. Aging Dis. 2018; 9:133-142.

58. Nelson G, Kucheryavenko O, Wordsworth J, et al. The senescent bystander effect is caused by ROS-activated NF- $\kappa$ B signaling. Mech Ageing Dev. 2018;170:30-36.

59. Theurey P, Pizzo P. The aging mitochondria. Genes. 2018;9:22.

60. Tan WJT, Song L, Graham M, et al. Novel role of the mitochondrial protein fus 1 in protection from premature hearing loss via regulation of oxidative stress and nutrient and energy sensing pathways in the inner ear. Antioxid Redox Signal. 2017;27:489-509.

61. García-Cazorla A, Wolf NI, Mochel F, et al. Neurological disease. In: Inherited Metabolic Diseases: A Clinical Approach Second Edition: Berlin, Germany Georg F, Hoffmann GF, Zschocke J, Nyhan WL, (eds.). SpringerVerlag GmbH: Berlin Heidelberg; pp. 251-292; 2018; Chapter 27.

62. Cao J, Wu H, Li Z. Recent perspectives of pediatric mitochondrial diseases (Review). Exp Ther Med. 2018;15:13-18.

63. Grier J, Hirano M, Karaa A, et al. Diagnostic odyssey of patients with mitochondrial disease. Neurol Genet. 2018;4:e230.

64. Kapnick SM, Pacheco SE, McGuire PJ. The emerging role of immune dysfunction in mitochondrial diseases as a paradigm for understanding immunometabolism. Metabolism. 2018;81:97-112.

65. Kuszak AJ, Espey MG, Falk MJ, et al. Nutritional interventions for mitochondrial OXPHOS deficiencies: mechanisms and model systems. Annu Rev Pathol Mech Dis. 2018;13:163-191.

66. Suomalainen A, Battersby BJ. Mitochondrial diseases: the contribution of organelle stress responses to pathology. Nat Rev Mol Cell Biol. 2018;19: 77-92.

67. Rosebush PI, Anglin RE, Rasmussen S, et al. Mental illness in patients with inherited mitochondrial disorders. Schizophr Res. 2017;187:33-37.

68. Cataldo LR, Olmos P, Smalley SV, et al. Mitochondrial DNA heteroplasmy of the m.3243A $>G$ mutation in maternally inherited diabetes and deafness. [In Spanish]. Rev Med Chil. 2013;141:305-312.

69. Davis RL, Liang C, Sue CM. Mitochondrial diseases. In: Handbook of Clinical Neurology, vol. 147 (3rd series). Neurogenetics, Part I. Geschwind $\mathrm{DH}$, Paulson HL, Klein C, (eds.). Elsevier: Amsterdam, Netherlands; pp. 125-141; 2018.

70. DiMauro S, Schon EA. Mitochondrial respiratory-chain diseases. N Engl J Med. 2003;348:2656-2668.

71. Ding Y, Leng J, Fan F, et al. The role of mitochondrial DNA mutations in hearing loss. Biochem Genet. 2013;51:588-602.

72. Finsterer J, Frank M. Maternally inherited diabetes and deafness is phenotypically and genotypically heterogeneous. J NeuroOphthalmol. 2016;36:346-347.

73. Thomas S, Gale Jr M. Mitochondria and antiviral immunity. In: Mitochondria and Cell Death. Hockenbery DM, (ed.). Springer: New York, NY; pp. 187-212; 2016; Chapter 10.

74. Mehta MM, Weinberg SE, Chandel NS. Mitochondrial control of immunity: beyond ATP. Nat Rev Immunol. 2017;17:608-620.

75. Lachmann HJ. Periodic fever syndromes. Best Pract Res Clin Rheumatol. 2018;31:596-609.

76. Yang J-L, Mukda S, Chen S-D. Diverse roles of mitochondria in ischemic stroke. Redox Biol. 2018;16:263-275.

77. Cohen BE, Durstenfeld A, Roehm PC. Viral causes of hearing loss: a review for hearing health professionals. Trends Hear. 2014;22:1-17.

78. Yun NE, Ronca S, Tamura A, et al. Animal model of sensorineural hearing loss associated with Lassa virus infection. J Virol. 2016;90: 2920-2927.
79. Byun $\mathrm{H}$, Chung $\mathrm{JH}$, Lee $\mathrm{SH}$, et al. Clinical value of 4-hour delayed gadolinium-enhanced 3D FLAIR MR images in acute vestibular neuritis. Laryngoscope. 2018 [Epub ahead of print]; DOI:10.1002/lary.27084.

80. Bhutta MF, Thornton RB, Kirkham L-AS, et al. Understanding the aetiology and resolution of chronic otitis media from animal and human studies. Dis Model Mech. 2017;10:1289-1300.

81. Bennett J, Capece D, Begalli F, et al. NF- $\kappa B$ in the crosshairs: rethinking an old riddle. Int J Biochem Cell Biol. 2018;95:108-112.

82. Miguel V, Cui JY, Daimiel L, et al. The role of microRNAs in environmental risk factors, noise-induced hearing loss, and mental stress. Antioxid Redox Signal. 2018;28:773-796.

83. Salinaro AT, Pennisi M, Di Paola R, et al. Neuroinflammation and neurohormesis in the pathogenesis of Alzheimer's disease and Alzheimerlinked pathologies: modulation by nutritional mushrooms. Immun Ageing. 2018;15:8.

84. Wong ACY, Ryan AF. Mechanisms of sensorineural cell damage, death and survival in the cochlea. Front Aging Neurosci. 2015;7:58.

85. Ghezzi $P$, Floridi $L$, Boraschi $D$, et al. Oxidative stress and inflammation induced by environmental and psychological stressors: a biomarker perspective. Antioxid Redox Signal. 2018;28:852-872.

86. McLean W. Toward a true cure for hearing impairment. Science. 2018; 359:1113.

87. Atilgan H, Town SM, Wood KC, et al. Integration of visual information in auditory cortex promotes auditory scene analysis through multisensory binding. Neuron. 2018;97:640-655

88. Flanagan S, Zorilă T-C, Stylianou $\mathrm{Y}$, et al. Speech processing to improve the perception of speech in background noise for children with auditory processing disorder and typically developing peers. Trends Hear. 2018; 22:1..

89. Sun T, Xu K, Ren Y, et al. Comprehensive molecular screening in Chinese Usher syndrome patients. Invest Ophthalmol Vis Sci. 2018;59:12291237.

90. Kimura Y, Masuda T, Kaga K. Vestibular function and gross motor development in 195 children with congenital hearing loss-assessment of inner ear malformations. Otol Neurotol. 2018;39:196-205.

91. Swanson, RL 2nd, Hampton S, Green-McKenzie J, et al. Neurological manifestations among US government personnel reporting directional audible and sensory phenomena in Havana, Cuba. JAMA 2018;319: 1125-1133.

92. Geng R, Omar A, Gopal SR, et al. Modeling and preventing progressive hearing loss in Usher syndrome III. Nat. Sci Rep. 2017;7:13480.

93. Chien WW. A CRISPR way to restore hearing. N Engl J Med. 2018;378: $1255-1256$.

94. Gao X, Tao Y, Lamas V, et al. Treatment of autosomal dominant hearing loss by in vivo delivery of genome editing agents. Nature. 2018;553:217221.

95. Kamakura T, O'Malley JT, Nadol Jr JB. Preservation of cells of the organ of Corti and innervating dendritic processes following cochlear implantation in the human: an immunohistochemical study. Otol Neurotol. 2018; 39:284-293.

96. Sakat MS, Kilic K, Bercin S. Pharmacological agents used for treatment and prevention in noise-induced hearing loss. Eur Arch Otorhinolaryngol. 2016;273:4089-4101.

97. Petremann M, Ba CTV, Broussy A, et al. Oral administration of clinical stage drug candidate SENS-401 effectively reduces cisplatin-induced hearing loss in rats. Otol Neurotol. 2017;38:1355-1361.

98. Dirain CO, Ng MRAV, Milne-Davies B, et al. Evaluation of mitoquinone for protecting against amikacin-induced ototoxicity in guinea pigs. Otol Neurotol. 2018;39:111-118.

99. Golbidi S, Li H, Laher I. Oxidative stress: a unifying mechanism for cell damage induced by noise, (water-pipe) smoking, and emotional stress-therapeutic strategies targeting redox imbalance. Antioxid Redox Signal. 2018;28:741-759.

100. Gilmore TD, Herscovitch M. Inhibitors of NF- $\kappa$ B signaling: 785 and counting. Nat Oncogene. 2006;25:6887-6899.

101. Steliou K, Boosalis MS, Perrine SP, et al. Butyrate histone deacetylase inhibitors. BioRes Open Access. 2012;1:192-198.

102. Galland L. The gut microbiome and the brain. J Med Food. 2014;17: 1261-1272.

103. Yedery RD, Jerse AE. Augmentation of cationic antimicrobial peptide production with histone deacetylase inhibitors as a novel epigenetic therapy for bacterial infections. Antibiotics. 2015;4:44-61. 
104. Zhang LS, Davies SS. Microbial metabolism of dietary components to bioactive metabolites: opportunities for new therapeutic interventions. Genome Med. 2016;8:46.

105. Liu H, Wang J, He T, et al. Butyrate: a double-edged sword for health? Adv Nutr. 2018;9:21-29.

106. Ying Z, Kampfrath T, Sun $Q$, et al. Evidence that $\alpha$-lipoic acid inhibits NF$\kappa \mathrm{B}$ activation independent of its antioxidant function. Inflamm Res. 2011;60:219-225.

107. Rochette L, Ghibu S, Muresan A, et al. Alpha-lipoic acid: molecular mechanisms and therapeutic potential in diabetes. Can J Physiol Pharmacol. 2015;93:1021-1027.

108. Chang MY, Gwon TM, Lee HS, et al. The effect of systemic lipoic acid on hearing preservation after cochlear implantation via the round window approach: a guinea pig model. Eur J Pharmacol. 2017;799:67-72.

109. Tibullo D, Volti GV, Giallongo C, et al. Biochemical and clinical relevance of alpha lipoic acid: antioxidant and anti-inflammatory activity, molecular pathways and therapeutic potential. Inflamm Res. 2017;66:947-959.

110. Zhao H, Bu M, Li B, et al. Lipoic acid inhibited desflurane-induced hippocampal neuronal apoptosis through Caspase3 and NF-KappaB dependent pathway. Tissue Cell. 2018;50:37-42.

111. Dixit $S$, Dhar $P$, Raj $D$, et al. Alpha lipoic acid (ALA) modulates expression of apoptosis associated proteins in hippocampus of rats exposed during postnatal period to sodium arsenite $\left(\mathrm{NaAsO}_{2}\right)$. Toxicol Rep. 2015;2:78-87.

112. Al-Rasheed N, Faddah LM, Hasan IH, et al. Amelioration of panadolinduced nephrotoxicity via down-regulation of $\mathrm{Bax} / \mathrm{Bcl} 2$ ratio with some antioxidants. Pharmacol Rep. 2017;69:1088-1093.

113. Sanadgol N, Golab F, Askari H, et al. Alpha-lipoic acid mitigates toxicinduced demyelination in the corpus callosum by lessening of oxidative stress and stimulation of polydendrocytes proliferation. Metab Brain Dis. 2018;33:27-37.

114. Rosini M, Simoni E, Bartolini M, et al. Exploiting the lipoic acid structure in the search for novel multitarget ligands against Alzheimer's disease. Eur J Med Chem. 2011;46:5435-5442.

115. Scumpia PO, Kelly-Scumpia K, Stevens BR. Alpha-lipoic acid effects on brain glial functions accompanying double-stranded RNA antiviral and inflammatory signaling. Neurochem Int. 2016;64:55-63.

116. Shirani A, Okuda DT, Stüve O. Therapeutic advances and future prospects in progressive forms of multiple sclerosis. Neurotherapeutics. 2016;13:58-69.

117. Cheng Y, Luo $F$, Zhang $Q$, et al. $\alpha$-Lipoic acid alleviates pentetrazolinduced neurological deficits and behavioral dysfunction in rats with seizures via an Nrf2 pathway. RSC Adv. 2018;8:4084-4092.

118. Sharif NA. iDrugs and idevices discovery research: preclinical assays, techniques, and animal model studies for ocular hypotensives and neuroprotectants. J Ocul Pharmacol Ther. 2018;34:7-39.

119. Zhang Y-H, Wang D-W, Xu S-F, et al. $\alpha$-Lipoic acid improves abnormal behavior by mitigation of oxidative stress, inflammation, ferroptosis, and tauopathy in P301S Tau transgenic mice. Redox Biol. 2018;14:535-548.

120. Liu R, Wang Y, Pu M, et al. Effect of alpha lipoic acid on retinal ganglion cell survival in an optic nerve crush model. Mol Vis. 2016;22:1122-1136.

121. Yamada T, Ogi K, Sakashita $M$, et al. Toll-like receptor ligands induce cytokine and chemokine production in human inner ear endolymphatic sac fibroblasts. Auris Nasus Larynx. 2017;44:398-403.

122. Hur DG, Kurabi A, Ryan AF. Screening antioxidants for the protection of cochlear sensory cells. Neural Regen Res. 2018;13:62-64.

123. Cronan JE. Assembly of lipoic acid on its cognate enzymes: an extraordinary and essential biosynthetic pathway. Microbiol Mol Biol Rev. 2016 80:429-450.

124. Steliou K, Faller DV, Pinkert CA, et al. Bioprotective carnitinoids: lipoic acid, butyrate, and mitochondria-targeting to treat radiation injury. Drug Dev Res. 2015;76:167-175.

125. Schüller ÁK, Canata DAM, Hackenhaar FS, et al. Effects of lipoic acid and $n$-3 long-chain polyunsaturated fatty acid on the liver ovariectomized rat model of menopause. Pharmacol Rep. 2018;70:263-269.

126. Shi $C$, Zhou X, Zhang J, et al. $\alpha$-Lipoic acid protects against the cytotoxicity and oxidative stress induced by cadmium in HepG2 cells through regeneration of glutathione by glutathione reductase via Nrf2/ ARE signaling pathway. Environ Toxicol Pharmacol. 2016;45:274-281.

127. Scangas GA, Bleier BS. Anosmia: differential diagnosis, evaluation, and management. Am J Rhinol Allergy. 2017;31:e3-e7.

128. Cuadrado A. NRF2 in neurodegenerative diseases. Curr Opin Toxicol. 2016;1:46-53.
129. Tavanai $E$, Mohammadkhani G. Role of antioxidants in prevention of age-related hearing loss: a review of literature. Eur Arch Otorhinolaryngol. 2017;274:1821-1834.

130. Someya S, Xu J, Kondo K, et al. Age-related hearing loss in C57BL/6 J mice is mediated by Bak-dependent mitochondrial apoptosis. Proc Nat Acad Sci U S A. 2009;106:19432-19437.

131. Polanski JF, Cruz OL. Evaluation of antioxidant treatment in presbyacusis: prospective, placebo-controlled, double-blind, randomised trial. J Laryngol Otol. 2013;127:134-141.

132. Chen J Hill K, Sha S-H. Inhibitors of histone deacetylases attenuate noiseinduced hearing loss. JARO. 2016;17:289-302.

133. Sarezky D, Raquib AR, Dunaief JL, et al. Tolerability in the elderly population of high-dose alpha lipoic acid: a potential antioxidant therapy for the eye. Clin Ophthalmol. 2016;10:1899-1903.

134. Hugdahl K, Sommer IE. Auditory verbal hallucinations in schizophrenia from a levels of explanation perspective. Schizophr Bull 2018;44:234241.

135. Lee TY, Lee J, Kim M, et al. The effect of transcranial direct current stimulation on auditory hallucination in patients with schizophrenia. Schizophr Res. 2018;192:489-490.

136. Yonutas HM, Vekaria HJ, Sullivan PG. Mitochondrial specific therapeutic targets following brain injury. Brain Res. 2016;1640:77-93.

137. Chan DK, Chang KW. GJB2-associated hearing loss: systematic review of worldwide prevalence, genotype, and auditory phenotype. Laryngoscope. 2014;124:E34-E53.

138. McGeer PL, McGeer E. Conquering Alzheimer's disease by self treatment J Alzheimers Dis. 2018;64:S361-S363.

139. Weinhouse C. Mitochondrial-epigenetic crosstalk in environmental toxicology. Toxicology. 2017;391:5-17.

140. Feinberg AP. The key role of epigenetics in human disease prevention and mitigation. N Engl J Med. 2018;378:1323-1334.

141. Nakano Y, Kelly MC, Rehman AU, et al. Defects in the alternative splicing dependent regulation of REST cause deafness. Cell. 2018 [Epub ahead of print]; DOI: 10.1016/j.cell.2018.06.004.

Cite this article as: Moos WH, Faller DV, Glavas IP, Harpp DN, Irwin MH, Kanara I, Pinkert CA, Powers WR, Steliou K, Vavvas DG, Kodukula K (2018) A new approach to treating neurodegenerative otologic disorders, BioResearch Open Access 7:1, 107-115, DOI: 10.1089/biores .2018.0017.

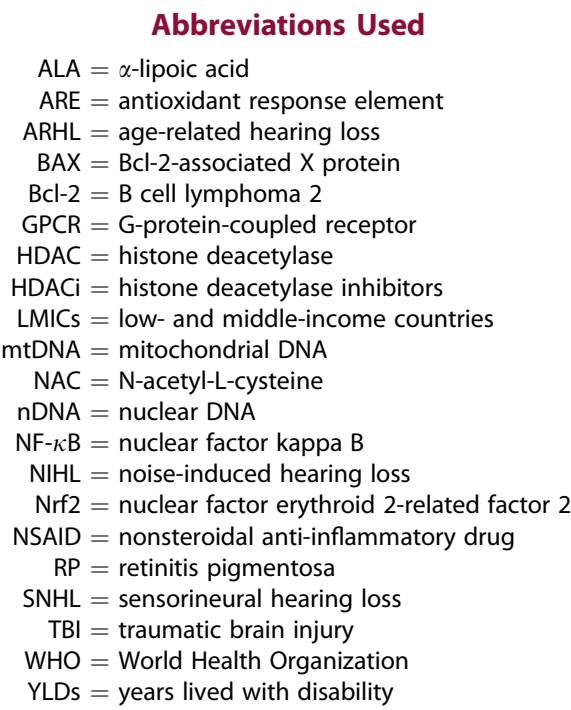

Abbreviations Used

$\mathrm{ALA}=\alpha$-lipoic acid

ARE $=$ antioxidant response element

$\mathrm{ARHL}=$ age-related hearing loss

$\mathrm{BAX}=\mathrm{BCl}$-2-associated $\mathrm{X}$ protein

$\mathrm{BCl}-2=\mathrm{B}$ cell lymphoma 2

$\mathrm{GPCR}=\mathrm{G}$-protein-coupled receptor

$\mathrm{HDAC}=$ histone deacetylase

$\mathrm{HDACi}=$ histone deacetylase inhibitors

LMICs $=$ low- and middle-income countries

mtDNA = mitochondrial DNA

$\mathrm{NAC}=\mathrm{N}$-acetyl-L-cysteine

nDNA $=$ nuclear DNA

$\mathrm{NF}-\kappa \mathrm{B}=$ nuclear factor kappa $\mathrm{B}$

$\mathrm{NIHL}=$ noise-induced hearing loss

$\mathrm{Nrf2}=$ nuclear factor erythroid 2-related factor 2

NSAID $=$ nonsteroidal anti-inflammatory drug

$\mathrm{RP}=$ retinitis pigmentosa

$\mathrm{SNHL}=$ sensorineural hearing loss

$\mathrm{TBI}=$ traumatic brain injury

WHO $=$ World Health Organization

YLDs $=$ years lived with disability 